\title{
Cobertura y accesibilidad a los servicios bancarios en España a escala urbana tras la Gran Recesión*
}

\author{
María Pilar Alonso Logroño \\ Universitat de Lleida. Departament de Geografia i Sociologia \\ pilar.alonso@udl.cat \\ Carlos López-Escolano \\ Universidad de Zaragoza. Departamento de Geografía y Ordenación del Territorio \\ cle@unizar.es
}

Raúl Postigo Vidal

Universidad de Zaragoza. Escuela de Turismo

rpostigo@unizar.es

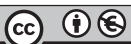

Recibido: junio de 2020

Aceptado: octubre de 2020

Publicado: abril de 2021

\section{Resumen}

La reestructuración financiera originada tras la Gran Recesión y la digitalización del sector presentan efectos territoriales en las ciudades españolas por la pérdida de la presencia física de sucursales bancarias. Este proceso está generando nuevos paisajes urbanos, pasando de una elevada presencia de oficinas en los distintos barrios a una escasez o ausencia de estos servicios en algunos espacios y a la concentración en otros. Este trabajo estudia estas dinámicas tomando como caso la ciudad de Zaragoza. El análisis realizado reconstruye el proceso de localización de las oficinas bancarias considerando la cobertura y valorando la accesibilidad de la población a los servicios financieros. La geolocalización de las oficinas bancarias desde la crisis de 2008 hasta 2019 y el empleo de información sociodemográfica desagregada permiten mostrar los espacios con problemas de acceso a estos servicios, mientras que el centro urbano vuelve a concentrar la actividad bancaria.

Palabras clave: reestructuración bancaria; estrategias territoriales; concentración; accesibilidad; cobertura; Zaragoza

* Este artículo se ha elaborado en el marco del proyecto «Indicadores multiescalares y herramientas cartográficas para el análisis de la vulnerabilidad socioeconómica y residencial en áreas urbanas: aplicación al caso de Zaragoza (PLOTEG2)» (CSO2016-74888-C4-3-R), del Programa Estatal de Investigación, Desarrollo e Innovación Orientada a los Retos de la Sociedad del Ministerio de Economía y Competitividad de España, convocatoria de 2016. Este proyecto participó en la Red Temática de Excelencia «Retos para las ciudades del siglo xxi: una agenda de investigación para la construcción de espacios urbanos sostenibles e innovadores», financiada por el Plan Estatal de Fomento de la Investigación Científica y Técnica de Excelencia 2013-2016 (referencia CSO2016-81718-REDT), coordinada por la Universidad Autónoma de Barcelona (julio de 2017 - junio de 2019). 
Resum. Cobertura $i$ accessibilitat als serveis bancaris a España a escala urbana després de la Gran Recessió

La reestructuració financera originada després de la Gran Recessió i la digitalització del sector presenten efectes territorials a les ciutats espanyoles per la pèrdua de la presència física de sucursals bancàries. Aquest procés està generant nous paisatges urbans, passant d'una elevada presència d'oficines als barris a una escassetat o absència d'aquests serveis en alguns espais i a la concentració en uns altres. Aquest treball estudia aquestes dinàmiques prenent com a cas la ciutat de Saragossa. L'anàlisi realitzada reconstrueix el procés de localització de les oficines bancàries considerant la cobertura i valorant l'accessibilitat de la població als serveis financers. La geolocalització de les oficines bancàries des de la crisi de 2008 fins a 2019 i l'ús d'informació sociodemogràfica desagregada permeten mostrar els espais amb problemes d'accés a aquests serveis, mentre que el centre urbà torna a concentrar l'activitat bancària.

Paraules clau: reestructuració bancària; estratègies territorials; concentració; accessibilitat; cobertura; Saragossa

Résumé. Couverture et accessibilité aux services bancaires en Espagne à l'échelle urbaine après la Grande Récession

Le processus de restructuration bancaire qui a vu le jour après la Grande Récession ainsi que la digitalisation du secteur bancaire ont des effets territoriaux pour les villes espagnoles. L'activité bancaire est passée d'une forte présence d'agences bancaires dans les villes à une rareté voire une absence dans certaines zones, avec une concentration dans d'autres. Ce travail étudie ces dynamiques en prenant la ville de Saragosse comme étude de cas. La géolocalisation des agences bancaires depuis la crise de 2008 jusqu'à 2019 et l'utilisation d'informations sociodémographiques très désagrégées permettent d'identifier les changements de localisation des agences bancaires. Pour ce faire, le processus de localisation des agences bancaires a été reconstruit, la couverture a été analysée et l'accessibilité de la population aux services financiers a été évaluée. De plus, le centre urbain est à nouveau un lieu de concentration de l'activité bancaire.

Mots-clés : restructuration bancaire; stratégies territoriales; concentration; accessibilité ; couverture; Saragosse

Abstract. Coverage and accessibility to banking services in Spain on the urban scale after the Great Recession

The financial restructuring process that originated after the Great Recession and the digitalization of the banking sector are having territorial effects on Spanish cities. This process is giving rise to new urban landscapes due to the loss of bank branches, which have gone from having a large presence in different neighborhoods to a scarcity or absence of branches in some spaces and a concentration in others. This work studies these dynamics taking the city of Zaragoza, Spain, as a case study. The analysis reconstructs the process of locating bank branches by examining coverage and assessing the population's accessibility to financial services. The geolocation of bank branches over the period 2008-2019 and the use of disaggregated socio-demographic information reveal spaces with problems of accessibility to bank services. Moreover, banking activity is once again concentrated in the urban center.

Keywords: bank restructuring; territorial strategies; concentration; accessibility; coverage; Zaragoza 


\section{Sumario}

$\begin{aligned} & \text { 1. Introducción } \text { 4. Fuentes estadísticas y aspectos } \\ & \text { 2. La reorganización bancaria y sus } \text { metodológicos } \\ & \text { dinámicas espaciales en España } \text { 5. La reorganización de la actividad } \\ & \text { 3. Cambios en los modelos de } \text { bancaria en la ciudad de Zaragoza } \\ & \begin{aligned} \text { localización bancaria en los espacios } & \text { 6. Conclusiones } \\ \text { urbanos. Estado de la cuestión } & \text { Referencias bibliográficas }\end{aligned}\end{aligned}$

\section{Introducción}

La Gran Recesión ha sido alcanzada pronto por otra crisis de ámbito global producto de los efectos de la pandemia internacional de la COVID-19. Las dos crisis se enlazan así en el tiempo, pues todavía seguimos registrando efectos socioeconómicos de la primera que, seguramente, se incrementarán con la actual, de acuerdo con las proyecciones realizadas por los organismos económicos (Banco de España, 2020a; Fondo Monetario Internacional, 2020). Uno de los sectores más perjudicados en la crisis anterior fue, sin duda, el financiero, y en la crisis pandémica actual también se refleja ya su afectación. La banca, con la crisis de 2008, se vio obligada a realizar una profunda reestructuración y transformación en la mayoría de los países, lo que provocó importantes cambios en el propio funcionamiento de las actividades bancarias y en las estrategias de organización espacial de los servicios que ofrecen a los clientes. Sin embargo, la reconversión del sector financiero no significa que haya perdido su importancia, puesto que la penetración de la actividad bancaria continúa aumentando tanto en el funcionamiento de las distintas actividades económicas como en la vida cotidiana de los ciudadanos (Méndez, 2018). Lo que se está modificando es su forma de funcionamiento, y esto afecta, entre otros aspectos, a las estrategias de localización espacial de las entidades.

En este contexto, España es uno de los países donde los efectos de la Gran Recesión han sido más notables, ya que la reorganización del sector bancario se ha llevado consigo buena parte del tejido financiero preexistente (Alonso Logroño et al., 2014a: 306). España acometió un proceso de fusiones y absorciones entre entidades muy duro (Fuentelsaz et al., 2016: 193), con las repercusiones que ello supone en las variables macroeconómicas y en las economías de familias y empresas (Tolentino et al., 2018: 142). Desde el punto de vista de la economía de las entidades financieras, este proceso ha sido aprovechado para mejorar su eficiencia ajustando la capacidad del sector y corrigiendo los desequilibrios (Jiménez Gonzalo y Tejero Sala, 2018: 38) tras un periodo de gran expansión (Alamá y Tortosa-Ausina, 2012). Con ello, se ha contribuido a solventar el exceso de capacidad instalada causado por el fuerte incremento del número de oficinas de los primeros años del siglo XXI (Gutiérrez Fernández et al., 2012). Como consecuencia, en el medio rural ha aumentado de forma preocupante el número de municipios sin oficina bancaria (Maudos Villarroya, 
2017), y de la misma manera, han sido muy elevados los cierres de sucursales en los entornos urbanos para evitar duplicidades tras los procesos de fusión y absorción. En las ciudades nos encontramos con una pérdida de diversidad empresarial y un reposicionamiento bancario en calles centrales frente al modelo de elevada proximidad practicado hasta 2008 (Alonso Logroño et al., 2014b). La configuración de «desiertos bancarios» en muchos espacios puede reforzar procesos de vaciamientos demográficos en el medio rural, así como de exclusión social y de pauperización urbana (Leyshon et al., 2008), ya que el cierre de oficinas también ha provocado la configuración de paisajes urbanos de crisis, para después dinamizar el mercado de locales comerciales en las ubicaciones centrales y estratégicas.

Sin embargo, la reducción de oficinas no significa una disminución del uso de los servicios bancarios, pues el grado de bancarización en España es muy elevado. Más del 93\% de la población adulta tiene una cuenta en un banco o institución financiera según datos del Banco Mundial (Demirgüç-Kunt et al., 2018), cifra que contrasta con la media global del 69\%. Esto significa que la población española, en su vida cotidiana, hace un importante uso de los servicios bancarios y ahora se enfrenta a una reducción en la accesibilidad física o presencial a los mismos.

En este contexto, en los últimos años estamos asistiendo también a la digitalización del sector con el paso del modelo tradicional y presencial a los nuevos modelos híbridos físico-digitales o, en muchos casos, únicamente virtuales. Ello es posible gracias a la automatización de los procesos de gestión, a la migración masiva hacia los canales digitales y a la centralización de los servicios (Ortaköy y Özsürünç, 2019). El despliegue de nuevas estrategias comerciales con el uso de la banca on-line es una de las apuestas principales del sector, que está desarrollando campañas muy fuertes para incentivar su uso, lo que, entre otros efectos, le está permitiendo realizar un ajuste más profundo en el proceso de cierre de sucursales.

El exceso en número de oficinas bancarias dificultó que en España se aplicaran con mayor rapidez las tecnologías digitales, pero la reducción del entramado físico de oficinas favorece ahora la aceleración del uso de las TIC en este tipo de actividades (Carbó, 2017). A esto también contribuyen los nuevos patrones de demanda social, cada vez más implicados en los procesos digitales, así como la presencia de nuevos competidores muy especializados en determinados servicios financieros, como las fintech (empresas apoyadas en nuevas tecnologías para ofrecer servicios financieros) o las firmas de comercio electrónico y telefonía (Amazon, Vodafone, Alibaba, Google), que también ofrecen servicios financieros (Molina, 2016; Rojas, 2016; Vives, 2019). Estos últimos tipos de empresas compiten con la banca tradicional, a la vez que generan improntas sociales y espaciales que es necesario valorar en los estudios sobre la implantación de los servicios financieros y captación de clientes. En ocasiones, atienden a nichos de mercados que quedan desatendidos por la banca tradicional y ofrecen actividades alternativas, muy especializadas, apoyadas en el mundo tecnológico y en las nuevas demandas sociales (Rojas, 2016). 
Algunos autores indican que la digitalización del sector podría mitigar, en parte, los efectos negativos del cierre de oficinas físicas (Chakravarty, 2006), si bien es cierto que las alternativas digitales excluyen a una parte de la población que no dispone de los medios o de las competencias digitales necesarias, principalmente la gente más mayor, por la brecha tecnológica, y las personas con menos recursos económicos (Maudos Villarroya, 2017; Jiménez Gonzalo y Tejero Sala, 2018). Recientemente, el confinamiento de la población y las limitaciones para la movilidad provocadas por la crisis sanitaria de la COVID19 han acentuado el uso de los canales digitales, pero también han puesto de manifiesto que no toda la población tiene la misma capacidad de acceso a los servicios financieros. Consecuentemente, la red de sucursales físicas sigue siendo un activo importante para la prestación de servicios bancarios (MartínOliver, 2018), ya que la proximidad mejora el acceso a los mismos al disminuir los costes de desplazamiento, además de crear redes de confianza entre las entidades y los clientes (Hauswald y Márquez, 2006). Asimismo, para los servicios bancarios más específicos - como la solicitud de préstamos, la concesión de hipotecas, la realización de inversiones o el asesoramiento fiscal, entre otros-, la oficina bancaria es todavía un activo fundamental para las entidades.

Desde una perspectiva geográfica, es relevante analizar las pautas seguidas para el diseño de los nuevos mapas bancarios presenciales y evaluar, entre otras consecuencias, el impacto que la reorganización del sector ha tenido sobre la accesibilidad física de la población a estos servicios.

En este contexto, este trabajo analiza algunos de los efectos provocados por la reorganización del sector financiero en España tras la crisis de 2008 y la situación causada por la COVID-19. Para ello, se toma la ciudad de Zaragoza como ejemplo de ciudad media española y se analiza cómo ha variado su mapa bancario en los últimos años: se estudia la trayectoria del cierre de sucursales desde el inicio del proceso de reorganización y se valora la cobertura (ratio de habitantes por oficina), junto con la accesibilidad territorial a las sucursales bancarias (posibilidad de acceso a una entidad financiera en función de la distancia), de acuerdo con distintos grupos de población según edad y renta. Ello permite observar la progresiva desigualdad espacial en el acceso a los servicios bancarios e identificar algunos patrones generales seguidos por las entidades en el proceso de reestructuración que pueden ayudar a comprender las dinámicas locacionales del sector bancario en las ciudades españolas.

El trabajo se organiza del siguiente modo: el apartado segundo analiza el proceso de reorganización bancaria en España y revisa sus principales impactos territoriales; el tercer epígrafe revisa el estado de la cuestión sobre los cambios en los modelos de localización bancaria en espacios urbanos; la sección cuarta presenta las fuentes estadísticas disponibles para el estudio territorial de las actividades financieras y de los métodos de análisis empleados en este trabajo; el quinto epígrafe muestra los resultados obtenidos para el caso de estudio de la ciudad de Zaragoza sobre la reorganización de la actividad bancaria y la localización de entidades, y por último la sección sexta recoge las principales conclusiones. 


\section{La reorganización bancaria y sus dinámicas espaciales en España}

La reestructuración que el sector financiero español ha vivido en poco más de una década es de gran envergadura, y cabe identificar tres aspectos fundamentales en su reconfiguración: el impacto de la crisis financiera de 2008, la digitalización de los servicios bancarios y, actualmente, los efectos de la pandemia de la COVID-19. En este contexto, el sistema financiero español ha pasado de 77 a 37 bancos $^{1}$, y de 48 cajas de ahorros a tan solo dos entre 2008 y 2020 (datos del segundo trimestre de 2020 del Boletín Estadístico del Banco de España). Este sistema se complementa con las cajas rurales, con un total de 29 cajas unidas en un grupo bancario único. Por su parte, los servicios de la banca electrónica han experimentado un gran crecimiento en España en los últimos años. Si en 2010 tan solo utilizaban la banca electrónica un 26\% de los usuarios de internet, en 2019 su uso ha aumentado hasta el 60\%, según los datos de la Encuesta sobre Equipamiento y Uso de Tecnologías de Información y Comunicación en los Hogares del INE. Cuando estos datos se actualicen en la próxima encuesta recogerán, con toda probabilidad, un gran incremento de su uso por la crisis sanitaria de la COVID-19, como avanzan algunos estudios (Europa Press, 2020). Resultado de estos procesos es la contracción del mercado financiero español en términos de diversidad de entidades, incentivada por una concentración sin precedentes auspiciada por la búsqueda de criterios de rentabilidad y eficiencia, y que ha implementado una gran pérdida de oficinas. En este sentido, los costes totales tras la reestructuración disminuyen para las entidades debido a los ahorros de las operaciones provocados por la reducción de sucursales, aun considerando los costes derivados del proceso de cierre físico: indemnizaciones a empleados, costes de la expansión digital y penalizaciones por la pérdida de clientes que abandonan la entidad al aumentar su distancia hasta las sucursales (Ruiz-Hernández et al., 2015).

Así, si en la etapa de bonanza anterior a la Gran Recesión aumentó de forma muy significativa el número de oficinas, desde la crisis de 2008 el proceso de reorganización de entidades - primero con fusiones y absorciones que provocaron enormes duplicidades en la red bancaria, y a lo que se sumó el proceso de digitalización - ha llevado a una importante reducción de oficinas, de 46.118 en 2008 a 24.004 a finales de 2019 (Banco de España, 2020b). El resultado ha sido la desaparición de cerca del 50\% de las sucursales bancarias que había en España, lo que supone casi la mitad de las cerradas en la zona euro (Martín-Oliver, 2018) y evidencia la fuerte afección de la reestructuración bancaria española.

La reducción en el exceso de capacidad física es una de las estrategias que están siguiendo las entidades financieras para ahorrar en locales y empleos, aunque ello suponga la configuración de nuevos desequilibrios en la provisión de servicios, ya que los cierres de oficinas se llevan a cabo, habitualmente, aten-

1. Esta cifra incluye la banca privada, de inversión, financiera y gestión de fondos, ya que el número de bancos comerciales ha pasado de 43 a 12, según los datos del Banco de España.

2. Caja de Ahorros y M. P. de Ontinyent y Colonya-Caixa d'Estalvis de Pollença. 
diendo a criterios de rentabilidad, sin ofrecer un equilibrio territorial (Delgado et al., 2008). Además, destaca la pérdida de casi 100.000 empleos en el sector, que pasan de 278.301 a 178.182 puestos de trabajo en el mismo periodo. Junto con estas consecuencias numéricas, otra que se ha tenido menos en cuenta y que, sin embargo, tiene una importante afección social es el aumento de la desigualdad en la provisión territorial de los servicios financieros (Maudos Villarroya, 2017). La falta de acceso físico es una de las cuestiones que tienen como consecuencia la exclusión financiera (Leyshon y Thrift, 1995, 1996), en especial en determinados territorios y grupos de población que se quedan sin banca física próxima para realizar sus gestiones, un problema destacado para la gente mayor, colectivo acostumbrado al uso del dinero en efectivo. La pandemia actual también ha empezado a provocar un nuevo proceso de cierre de oficinas, ante la necesidad de reducir costes y por el giro que han dado los clientes hacia un incremento en el uso de los canales digitales durante el confinamiento.

De este modo, muchos municipios pequeños se han quedado sin ninguna oficina, y cada vez es mayor la población que tiene problemas de acceso a una sucursal física bancaria. En 2015, de acuerdo con Maudos Villarroya (2017: 286), solo un $2,4 \%$ de la población española no podía acceder físicamente a los servicios de una oficina bancaria en su lugar de residencia, proporción que aumenta al 2,7\% a finales de 2016 (Jiménez Gonzalo y Tejero Sala, 2018: 43) y que alcanza el 2,9\% en 2017 (IVIE, 2018), después de que más de 4.100 municipios vieran como cerraba su única oficina. En concreto, el 52,2\% de los municipios no tenían ya en 2017 ninguna sucursal física, según el Instituto Valenciano de Investigaciones Económicas (IVIE). En las poblaciones de menor tamaño, el impacto ha sido superior, ante la menor oferta inicial y el cierre de sucursales de cajas de ahorros, tipo de entidad financiera predominante en estas zonas (Maudos Villarroya, 2014: 103). En estos espacios, al cierre de oficinas se ha sumado el desmantelamiento de la red de cajeros automáticos que complementan los servicios bancarios y satisfacen las demandas de efectivo, compensado solamente en algunas zonas por el uso de oficinas móviles u ofibuses, o por la figura de los agentes financieros que atienden a los clientes donde ya no existe oficina bancaria (Jiménez Gonzalo y Tejero Sala, 2018: 39). Además, muchas de estas zonas se enfrentan a problemas de conectividad digital, por la falta de acceso o por la baja calidad de internet.

Pero, junto a los pequeños municipios, también en los espacios urbanos se aprecian las consecuencias de la reorganización bancaria, ya que en la mayoría de las ciudades las oficinas se han reducido a la mitad. Madrid ha pasado de más de 3.000 en 2010, según datos del Anuario de Caja España, a 1.799 en 2017, según la base del IVIE; Valencia, de 940 a 489; Barcelona, de 1.717 a 975, o Valladolid, de 331 a 162 oficinas. Los repliegues en las redes de oficinas han sido muy altos, lo que ha llevado a las áreas urbanas a una reorganización espacial de los servicios bancarios, con transformaciones en su funcionalidad, actividad y proximidad a la población mediante la implantación de modelos de redes bancarias físicas que potencian los espacios centrales o los ejes fun- 
Figura 1. Ratio de habitantes por oficina en las principales ciudades, 2001-2017

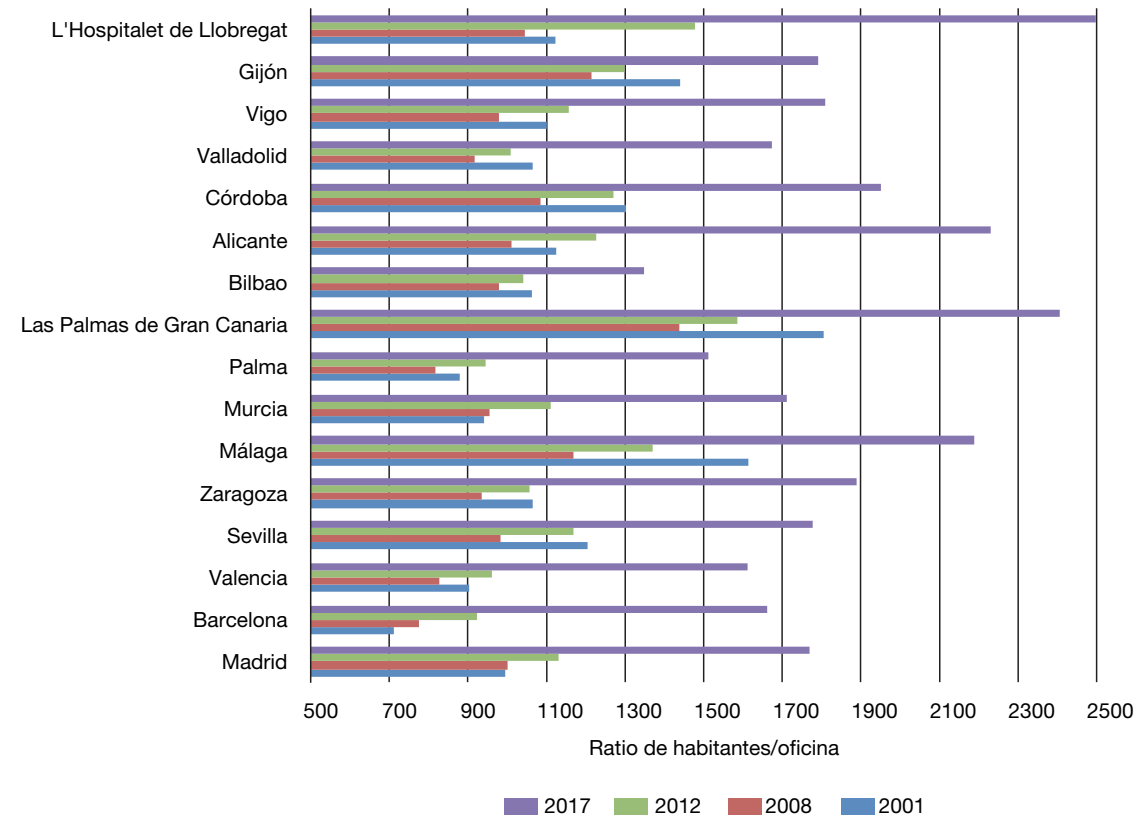

Fuentes: INE (población), Anuario Estadístico La Caixa e IVIE (número de oficinas). Elaboración propia, 2020.

cionales de los barrios tradicionales (Alonso Logroño et al., 2014b: 413). Ello deja muchas áreas sin oficinas o con muy poca diversificación de entidades, de forma que se pasa de un servicio donde predominaba un modelo de proximidad a otro de concentración y centralidad. La situación resultante es que cada vez las oficinas tienen que atender a más clientes.

Un indicador básico para medir la cobertura de las entidades financieras es la ratio de número de clientes por oficina. La figura 1 muestra esta relación para las principales ciudades españolas, donde se aprecian diferencias muy notables. Todas las ciudades analizadas han visto incrementar los valores de sus ratios a partir de 2008, lo que supone un empeoramiento de la disponibilidad de los servicios bancarios físicos para la población. Entre las ciudades con mejor situación en 2017, se sitúan Bilbao, Palma, Valencia, Valladolid y Barcelona, con ratios por debajo de los 1.700 habitantes por oficina; mientras que Hospitalet de Llobregat, Las Palmas, Alicante y Málaga superan los 2.000 habitantes por sucursal. Respecto a 2008, los mayores incrementos porcentuales del valor de la ratio se han dado en Hospitalet de Llobregat $(139,2 \%)$, Alicante $(120,2 \%)$ y Barcelona (114,1\%), espacios donde se han producido procesos de reestructuración muy importantes por parte de entidades con fuerte implantación territorial (Catalunya Caixa, CaixaBank, Bankia, CAM). Por 
el contrario, incrementos más bajos se han dado en Bilbao (37,7\%), Gijón (47,5\%) o Las Palmas (67,3\%).

A pesar de las pérdidas de oficinas y empleos, España continúa siendo uno de los países europeos con mayor número de habitantes por sucursal, aunque ahora la diferencia de esta ratio con relación a otros países es sustancialmente más baja que antes de la crisis financiera (Jiménez Gonzalo y Tejero Sala, 2018: 38). Si en 2008 la media española de clientes por oficina presentaba una ratio de 999, a finales de 2019 esta cifra ha pasado a 1.959, muy lejos todavía de la media europea de 2.500 clientes por oficina (Banco Central Europeo, 2019; Banco de España, 2020b). En este sentido, la crisis de la COVID-19 reforzará muy probablemente este aspecto, y de ahí el interés en profundizar en esta línea de investigación, ya que con la actual pandemia los procesos de reorganización financiera se están intensificando y se está reduciendo aún más la presencia física de los servicios bancarios. La situación provocada por el confinamiento total durante la pandemia supuso un posible escenario de ensayo para nuevos cierres de oficinas — que ya se ha empezado a producir- y de una nueva ola de fusiones entre entidades.

Durante el periodo de confinamiento, los servicios bancarios se consideraron esenciales, aunque ante la falta de usuarios las entidades desplegaron diferentes estrategias para mantener los servicios básicos presenciales durante la crisis sanitaria mediante una reducción temporal de las sucursales abiertas. En general, cabe destacar la diferencia entre las coberturas ofrecidas por los bancos de la AEB (Asociación Española de Banca), que han cerrado la mitad de sus oficinas, y las antiguas cajas de ahorros de la CECA (Confederación Española de Cajas de Ahorros), que han mantenido abiertas el 90\% de sus sucursales (Zuloaga, 2020). Concretamente, Ibercaja ha cerrado únicamente el $5 \%$ de sus oficinas, Cajamar el $11 \%$, y CaixaBank y Bankia el $12 \%$; frente a una reducción del 47\% del Santander, del 69\% de BBVA y del 50\% de Bankinter, entre otras entidades. Estos datos pueden ser muestra de los nuevos niveles de servicio que podrían consolidarse en el futuro, aunque la creación del primer banco español por activos tras la fusión entre CaixaBank y Bankia va a conllevar el cierre de un importante número de oficinas, en especial en los territorios donde ambas entidades cuentan con mayor presencia, como Madrid, Andalucía o la Comunidad Valenciana (El Periódico, 2020; Romero, 2020). En el mismo sentido, los cierres van a ser numerosos en provincias como Cáceres, León, Salamanca o Toledo por la fusión entre Unicaja y Liberbank (Díaz, 2020).

Muchas de las oficinas cerradas temporalmente durante la pandemia ya no volverán a abrir, y se estima que cerca de 4.000 cerrarán entre 2020 y 2021, de modo que pasarán de las 24.000 de finales de 2019 a 19.900 en 2021, como indican algunos analistas económicos (Gonzalo, 2020). Por ejemplo, en 2020 CaixaBank, antes de su fusión con Bankia, ya había decidido cerrar más de 400 oficinas, mientras que Bankia ha cerrado 145, BBVA 160 e Ibercaja tiene previsto el cierre de 60 oficinas más. Las entidades financieras, ante la nueva situación, han optado por intensificar los cierres para reducir costes y reforzar el uso de los canales digitales. 


\section{Cambios en los modelos de localización bancaria en los espacios urbanos. Estado de la cuestión}

Las investigaciones realizadas sobre la localización de los servicios financieros en los espacios urbanos son numerosas por su interés en las dinámicas y procesos de configuración urbana. En primer lugar, cabe señalar algunos trabajos ya clásicos sobre la localización general de las actividades económicas, entre las que se encuentran los servicios bancarios (Isard, 1956; Moses y Williamson, 1967; Labasse, 1974), que, en general, apuntan en sus explicaciones a factores como la demanda de la clientela mediante la proximidad y la búsqueda de centralidad para explicar la localización financiera. De forma específica, otros autores que han abordado el estudio de los factores de localización de las sucursales bancarias, como Moreno y Escolano (1992), Boufounou, (1995), García Cabello (2019) y Jackowicz et al. (2020), presentan resultados coincidentes en cuanto a la selección de los criterios de rentabilidad que rigen en las entidades para ubicar sus oficinas: número potencial de clientes, situación socioeconómica del vecindario, características comerciales y empresariales del entorno, facilidad de acceso a las sucursales y antigüedad de la oficina como factor crucial para retener depósitos.

Respecto a las dinámicas urbanas del sector bancario, Garrocho-Rangel y Campos-Alanís (2010) abordan la localización de los servicios financieros en Toluca (México) desde la triple perspectiva de la estrategia de ubicación de las sucursales, de las desigualdades de acceso y de los factores de localización. Estudian estas dimensiones mediante diferentes métodos de análisis espacial observando una evolución de la estructura espacial del sistema bancario de un modelo monocéntrico a otro policéntrico. Interpretan la estrategia de localización sobre la base de la orientación a segmentos específicos (servicios públicos y privados, población con mayores ingresos), la organización en clústeres para aprovechar las economías de aglomeración y la ubicación en las calles más importantes. Los resultados identifican las barreras de acceso de la población vulnerable provocadas por la estructura de la red de sucursales, lo que remarca la significación del estudio de la localización bancaria. Por otra parte, Huysentruyt et al. (2013) analizan los patrones de implantación de las sucursales bancarias entre 1991 y 2006 en la ciudad de Amberes (Bélgica), en un momento de reestructuración previo a la Gran Recesión pero que marca los cambios posteriores. Su trabajo evidencia el aumento de las zonas urbanas que no disponen de sucursal bancaria y, además, que estas se asocian a barrios donde los ingresos medios son escasos, lo que incrementa la segregación.

De forma reciente, han surgido aportaciones que proporcionan metodologías para el redimensionamiento de las redes bancarias tras los procesos de reorganización (Ruiz-Hernández et al., 2015) y otras enfocadas a la cuantificación de sus efectos en la provisión territorial de estos servicios. En este último ámbito, destaca la literatura española, muy desarrollada para el análisis de este proceso y sus consecuencias por la magnitud del proceso de 
reorganización bancaria vivido en España frente al de otros países del entorno durante la Gran Recesión. En esta línea se centran los trabajos de Alamá y Tortosa-Ausina (2012); Gutiérrez Fernández et al. (2012), Alonso Logroño et al. (2014a), Maudos Villarroya (2014; 2017), Fuentelsaz et al. (2016) o Jiménez Gonzalo y Tejero Sala (2018). Sin embargo, las aportaciones recientes son menos frecuentes en los estudios de las dinámicas espaciales a escala urbana. Alonso Logroño et al. (2014b) analizan los primeros impactos de la Gran Recesión en la reorganización local de la banca en la ciudad de Zaragoza, para lo que estudian la evolución global de oficinas y su distribución en la ciudad e indican que el proceso de reestructuración bancaria ha empeorado la cobertura bancaria, sobre todo en los barrios populares y envejecidos, procesos que también se detectan en otras ciudades (Alonso Logroño et al., 2020). Por su parte, Fernández-Olit et al. (2019) han analizado para Madrid y Barcelona la exclusión financiera tras la crisis desde la perspectiva de los colectivos vulnerables mediante un novedoso análisis a microescala. En él se centran en identificar los principales determinantes de la discriminación financiera territorial de acuerdo con perfiles socioeconómicos mediante un método de regresión cuantil que incluye numerosas variables (ratio de oficinas por habitante, densidad de población, porcentaje de población mayor de 65 años, porcentaje de población extranjera, desempleo, renta, hoteles, precio de la vivienda y acceso a internet). Sus resultados confirman cómo las sucursales más saturadas se encuentran en espacios con un perfil socioeconómico más bajo, y con ello evidencian un empeoramiento de la calidad de los servicios de atención al cliente, lo que aumenta las dificultades de uso de los grupos vulnerables con menores destrezas tecnológicas y cultura financiera, ambos esenciales para operar en un sector bancario digitalizado y de bajo coste.

En cualquier caso, todos los trabajos que se aproximan a las dinámicas espaciales de la banca en España a escala urbana confirman que se ha terminado con el modelo de gran accesibilidad espacial entre usuarios y oficinas fruto de la expansión de las actividades financieras desde los años ochenta. Frente a este modelo, la crisis de 2008 y la reestructuración que se está produciendo están llevando al repliegue de oficinas hacia el centro urbano y hacia zonas de mayor intensidad de actividades, como los centros de los barrios y los ejes viarios de mayor circulación de personas.

En esta sección hemos reflexionado sobre cómo las nuevas situaciones surgidas tras la crisis en el sector bancario se han traducido en nuevos modelos de organización territorial que están incidiendo en un repliegue de la oferta de sucursales a escala urbana con coberturas menguantes en los espacios más desfavorecidos. La banca digital podría suplir en parte estas carencias, aunque no para todos los grupos de población. Como ya apunta algún estudio, es probable que, una vez que la clientela haya migrado mayoritariamente a los canales digitales y se hayan eliminado la mayor parte de oficinas físicas, se incrementen los precios de los servicios digitales, lo que generará nuevos procesos de marginación (Kempson, 2006). 


\section{Fuentes estadísticas y aspectos metodológicos}

Para aproximarse al conocimiento de las dinámicas espaciales de la actividad bancaria en España, hemos utilizado en la sección anterior datos del Banco Central Europeo y del Boletín Estadístico del Banco de España, que recopilan y publican datos de oficinas, empleo y entidades desagregados por provincias ${ }^{3}$. También hemos usado información del Instituto Valenciano de Investigaciones Económicas (IVIE, 2018 ) y datos del antiguo anuario de Caja España, fuentes que proporcionan una base de datos sobre el número de oficinas por municipio con referencia al año 2017 la primera y de datos anteriores a 2011 la segunda. Algunas de las fuentes de información más utilizadas que permitían conocer a escala municipal la implantación territorial de las actividades financieras dejaron de publicarse coincidiendo con la crisis de 2008, como los Anuarios de Caja España y de La Caixa.

Para acercarnos a la interpretación de las nuevas dinámicas espaciales de la banca en las ciudades y ver los cambios de accesibilidad, se ha tomado como caso de estudio la ciudad de Zaragoza, ejemplo de ciudad media y centro regional con una amplia diversidad de actividades bancarias (Zuliani, 2013), aunque estas se están reorganizando con especial intensidad desde 2008 (Alonso Logroño et al., 2014b).

En el análisis realizado, se ha optado por emplear una base de datos espaciales elaborada por el Grupo de Estudios en Ordenación del Territorio (GEOT) de la Universidad de Zaragoza, que reconstruye la historia reciente de todas las localizaciones de oficinas bancarias en el municipio de Zaragoza desde el año 2001 hasta 2019. En esta base se incluyen todos los locales que alberguen o han tenido una sucursal física en este periodo. El proceso de recogida de información es sistemático y multitemporal, con la actualización una vez al año de la información mediante la consulta de las páginas web oficiales de las entidades bancarias y la verificación posterior a través de trabajo de campo del estado y los servicios disponibles de cada oficina. Con esta información, se han georreferenciado sobre la base espacial de Zaragoza las ubicaciones de oficinas y se ha creado una base de datos con diferentes atributos: nombre, grupo bancario, estado (cerrado/abierto) o disponibilidad de cajero. Asimismo, la base de datos incorpora el código único del portal, manzana, sección censal y distrito donde se localiza la oficina, para poder presentar agregaciones de datos y abordar estudios multiescalares. Este sistema de codificación también permite realizar uniones con información sociodemográfica (datos del padrón municipal de habitantes) o de renta. Con ello, es posible diagnosticar la afección

3. Junto con esta fuente, los propios anuarios de la Asociación de la Banca española (AEB) y la Asociación de Cajas (CECA) ofrecen también datos a escala provincial de entidades y oficinas, así como otros datos financieros, aunque no tienen el formato de descarga web que aporta el Banco de España.

4. El IVIE es un centro de investigación dedicado a desarrollar y fomentar las investigaciones nacionales e internacionales, entre cuyos cometidos está generar bancos de datos como el utilizado. 
del cierre de oficinas a los diferentes espacios urbanos y grupos de población (según localización, edad, nivel de ingresos, etcétera) para identificar patrones espaciales y áreas con dificultad de acceso a la banca física.

La metodología seguida se ha apoyado en los primeros apartados de este trabajo en análisis del estado de la cuestión de los efectos que la reestructuración financiera ha tenido en las dinámicas de localización del sector bancario. La segunda parte de este trabajo, la aproximación al estudio de la cobertura y la accesibilidad a escala urbana, se ha abordado mediante el cálculo de diferentes variables y la representación cartográfica de los resultados:

1. La distribución espacial del estado de las oficinas (abiertas/cerradas) y su relación con la base cartográfica de población por manzanas y distritos para conocer la cobertura o ratio de habitantes por oficina. Para ello, se valora la evolución temporal del cierre de oficinas en tres periodos diferentes: 2001-2008, 2009-2013 y 2014-2019. Los cierres se representan cartográficamente en el mismo plano que las oficinas abiertas y que mantienen el servicio en la actualidad, con el objetivo de comparar la dotación anterior y la actual.

2. La accesibilidad de la población a las entidades financieras a 300 metros de su residencia, valorando el número de entidades (marcas bancarias) diferentes accesibles en entornos de proximidad idóneos para los desplazamientos a pie o en bicicleta que aseguran una accesibilidad para el conjunto de la población. La distancia umbral de 300 metros ha sido seleccionada de acuerdo con los criterios definidos por la Agenda 21 como distancia óptima de la población a los servicios básicos y de uso frecuente, entre los que se encuentra la actividad bancaria. Considerando el centroide de la manzana, se calcula una distancia euclidiana de 300 metros para seleccionar todas aquellas entidades diferentes que se encuentran en servicio. Posteriormente, una selección espacial permite realizar un sumatorio por manzana y clasificar niveles de diversidad financiera $(0,1,2,3,4,5$ o 6 y más entidades diferentes a menos de 300 metros). Finalmente, los centroides se representan por símbolos proporcionales que muestran el total de población de la manzana. Esta información se proporciona para los años 2011 y 2019, con desagregación por sección censal para ambos años y con detalle por manzana para el escenario más actual de 2019.

3. La relación espacial entre el nivel de renta, la población de 65 y más años y el cierre de oficinas. Con información de Urban Audit de Eurostat (2016), se representan los niveles de renta personal media por sección censal. A partir de esta, se ha realizado una unión espacial para obtener un promedio del porcentaje de población de 65 y más años, así como un sumatorio de todas las oficinas cerradas hasta la fecha en cada sección censal. La cartografía representa los resultados a través de un cuadro de doble entrada que permite localizar dónde se encuentran las zonas más envejecidas y de menor renta, y comprobar si existe una correlación espacial con las zonas que más han sufrido la reorganización financiera. En el mapa de base, se incorpora 
por tonalidades de grises la tasa de desempleo con el objetivo de reforzar el análisis socioeconómico.

Explorar todos estos aspectos, en áreas y escalas concretas, permite comprender mejor la lógica de la implantación espacial del sistema bancario tras la reorganización de las entidades acaecida en los últimos años, así como anticipar posibles nuevas dinámicas que ya se están iniciando fruto de la crisis de la COVID-19 y de la nueva ola de fusiones prevista en el sistema bancario español. Con los resultados, se quiere obtener un mayor conocimiento de estas pautas, especialmente útiles para la planificación urbana y la provisión de servicios a la población, así como abrir una ventana para la investigación de algunas de sus consecuencias, como la aparición de desiertos bancarios y los problemas de exclusión financiera para una parte de la población. Los resultados, presentados mediante cartografía, se analizan tanto a escala de ciudad como por juntas de distrito (nivel administrativo oficial del municipio de Zaragoza), e incluso unidades inferiores como las secciones censales y manzanas para algunos análisis.

\section{La reorganización de la actividad bancaria en la ciudad de Zaragoza}

La ciudad de Zaragoza, como la mayoría de las ciudades grandes y medias españolas, comienza el siglo xxi con un importante incremento en el número de sucursales que supone una fuerte bancarización física del espacio urbano, para aproximar las oficinas a la población y a las actividades productivas con el objetivo de captar más recursos. Sin embargo, la situación después de la crisis financiera es la de un sector bancario mucho menos presente en el espacio físico, donde predominan los principios más clásicos de la localización financiera: el centro urbano y los espacios de mayor actividad y circulación peatonal en los barrios (Labasse, 1974; Moreno y Escolano, 1992). Esta actividad desaparece o es muy escasa en los barrios de rentas bajas, en las zonas poco densas, con escasas actividades económicas, y en los barrios de reciente desarrollo.

El impacto de los procesos de reestructuración bancaria entre entidades y de la consecuente reorganización del modelo de atención física en sucursales ha llevado a una reducción drástica del número de oficinas. De forma concreta, Zaragoza pasa entre 2001 y 2008 de contar con 574 sucursales a 676, que se reducen a 351 a finales del año 2019, lo que supone una pérdida de más del $48 \%$ de los puntos de atención física respecto al año de mayor implantación. La figura 2 permite reconstruir espacialmente la ubicación de la actividad bancaria en la ciudad a lo largo de este periodo. La variación total del número de sucursales muestra claramente tres periodos diferenciados: i) el momento expansivo previo a la crisis entre 2001 y 2008 (172 nuevas oficinas), ii) los primeros efectos de la reorganización del sector financiero tras la crisis entre 2009 y 2013 (144 oficinas cerradas), y iii) las variaciones más recientes con el repliegue de la red desde 2014 a 2019 (100 nuevas oficinas cerradas, 244 cerradas acumuladas respecto a 2008). Por años, 2014 registró el mayor 
Figura 2. Distribución y evolución de los cierres de oficinas bancarias en la ciudad de Zaragoza, 2001-2019

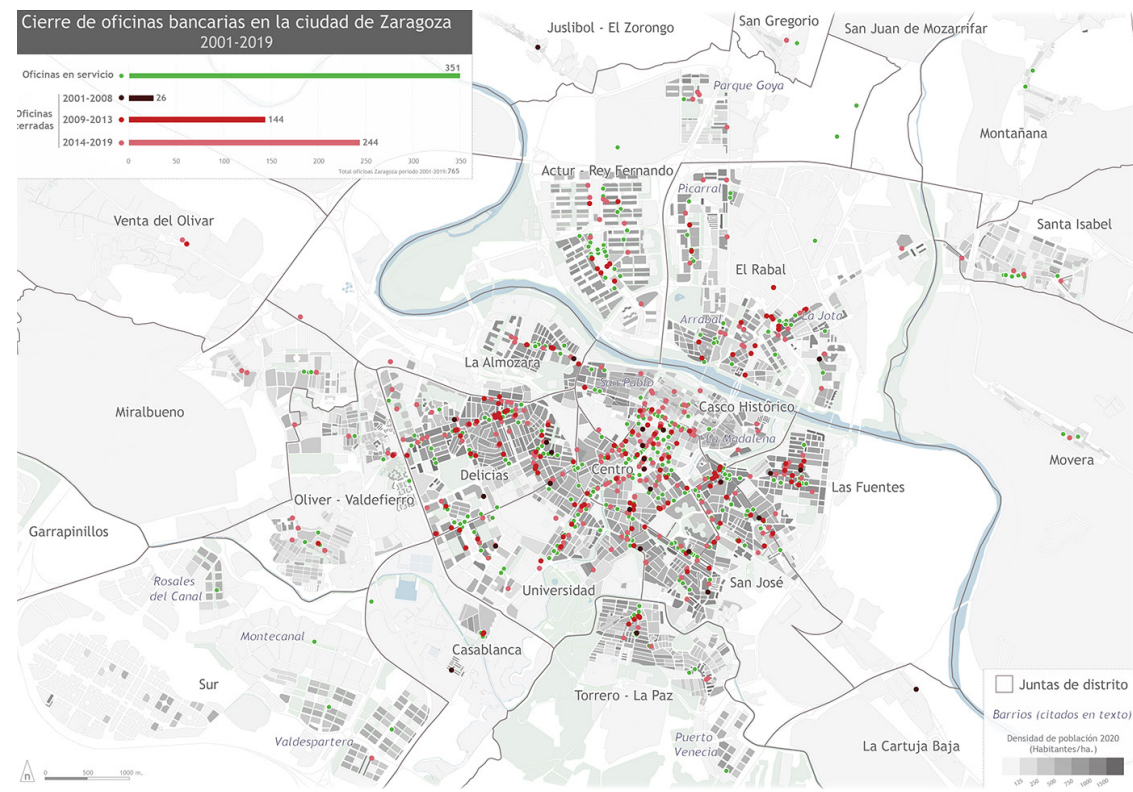

Fuentes: Padrón Municipal de Habitantes del Ayuntamiento de Zaragoza y Grupo de Estudios en Ordenación del Territorio. Elaboración propia, 2020.

número de cierres (86), seguido de 2013 (61), 2018 (56) y 2019 (41). En el último periodo (2014-2019), este repliegue ha sido incluso más fuerte que el inmediatamente posterior a la crisis y ha coincidido con el momento de mayor auge de los procesos de cierre de sucursales, que evitan crear redes duplicadas por parte de las entidades resultantes de la reorganización del sector, pero también por la aplicación de nuevas estrategias para afrontar la digitalización masiva de la banca.

Por su parte, la ratio de habitantes por oficina en 2008 era muy baja (934 personas por sucursal), lo que permitía hablar de una ciudad con un espacio fuertemente bancarizado antes de la crisis financiera (Alonso Logroño et al., 2014b: 414-415). Así, se cumplía uno de los rasgos de este tipo de servicios como es disponer de una elevada proximidad a los clientes, con un reparto por todas las áreas de la ciudad como estrategia de expansión y crecimiento. En 2019, la ratio escaló a una media de 2.067 clientes por oficina, lo que supone una elevada saturación en determinados espacios donde este indicador es más elevado (tabla 1). Uno de los primeros efectos, y tal vez el más visible, es el cambio en el paisaje urbano de este tipo de actividades. Zaragoza ha pasado de disponer de 64 entidades bancarias diferentes a tener tan solo 24 en 2019, cifra que se recortará en otras dos en el corto plazo por la fusión entre CaixaBank 
Tabla 1. Características sociodemográficas (2019), oficinas abiertas (2019), oficinas cerradas (2001-2019) y ratio habitantes por oficina (2019) en los distritos de la ciudad de Zaragoza

\begin{tabular}{|c|c|c|c|c|c|c|c|c|}
\hline Distrito & Población & $\begin{array}{c}\text { Oficinas } \\
\text { abiertas } \\
2019\end{array}$ & $\begin{array}{c}\text { Oficinas } \\
\text { cerradas } \\
2001-2019\end{array}$ & $\begin{array}{c}\text { Ratio } \\
\text { hab./oficina } \\
2019\end{array}$ & $\begin{array}{l}\text { Porcentaje de } \\
\text { población menor } \\
\text { de } 24 \text { años }\end{array}$ & Sobreenvejecimiento & Envejecimiento & $\begin{array}{c}\text { Renta personal } \\
\text { media (euros) }\end{array}$ \\
\hline Centro & 53.436 & 82 & 93 & 651,7 & 19,2 & 20,1 & 277,2 & $17.936,9$ \\
\hline Universidad & 50.747 & 34 & 30 & $1.492,6$ & 21,8 & 21,1 & 222,5 & $16.347,4$ \\
\hline Barrios Rurales & 31.551 & 20 & 23 & $1.577,6$ & 23,3 & 21 & 196,6 & $12.742,2$ \\
\hline Delicias & 104.563 & 52 & 74 & $2.010,8$ & 20,1 & 18,5 & 234,4 & $11.227,6$ \\
\hline Actur-Rey Fernando & 58.714 & 27 & 21 & $2.174,6$ & 26,6 & 12,7 & 115,5 & $12.609,7$ \\
\hline San José & 67.678 & 31 & 36 & $2.183,2$ & 19,8 & 19,1 & 230,0 & $11.430,1$ \\
\hline Santa Isabel & 13.492 & 6 & 6 & $2.248,7$ & 30,8 & 19,8 & 65,6 & $11.795,4$ \\
\hline Casco Histórico & 47.210 & 20 & 26 & $2.360,5$ & 20,5 & 21,6 & 180,1 & $11.985,0$ \\
\hline Casablanca & 10.395 & 4 & 3 & $2.598,8$ & 24,9 & 16,8 & 191,0 & $15.194,4$ \\
\hline El Rabal & 79.162 & 29 & 38 & $2.729,7$ & 26,1 & 15,3 & 119,9 & $11.269,9$ \\
\hline Torrero-La Paz & 42.473 & 12 & 11 & $3.539,4$ & 24,0 & 18,5 & 123,8 & $10.462,9$ \\
\hline La Almozara & 30.098 & 8 & 14 & $3.762,3$ & 19,6 & 16,0 & 242,9 & $12.157,3$ \\
\hline Las Fuentes & 43.003 & 12 & 25 & $3.583,6$ & 21,0 & 18,2 & 218,1 & $10.192,8$ \\
\hline Miralbueno & 12.806 & 3 & 4 & $4.268,7$ & 33,7 & 16,3 & 37,0 & $13.521,8$ \\
\hline Oliver-Valdefierro & 32.474 & 7 & 9 & $4.639,1$ & 27,8 & 13,1 & 94,0 & $11.779,0$ \\
\hline Sur & 38.774 & 4 & 1 & $9.693,5$ & 32,5 & 10,5 & 17,3 & $14.594,9$ \\
\hline Zaragoza & 716.576 & 351 & 414 & 2.067 & 24,5 & 17,4 & 160,4 & $12.828,0$ \\
\hline
\end{tabular}

Fuentes: Padrón Municipal de Habitantes del Ayuntamiento de Zaragoza y Grupo de Estudios en Ordenación del Territorio. Elaboración propia, 2020.

y Bankia, así como entre Unicaja y Liberbank, entidades con mayor o menor presencia en la ciudad (Sampedro, 2020).

En este contexto, la población y las empresas se enfrentan cada vez más a la falta de entidades y oficinas en sus entornos de proximidad, aunque no todo el espacio urbano aprecia este proceso por igual. Casi todos los distritos urbanos han registrado una pérdida superior al $50 \%$ de sus oficinas, pero algunas zonas han quedado mucho más afectadas que otras. El distrito Centro, que reunía antes de la crisis el mayor número de sucursales (175), se ha visto muy afectado entre 2008 y 2019 (93 oficinas cerradas), aunque continúa siendo el área con mayor número de sucursales y mejor ratio de habitantes por oficina entre los distritos urbanos (651,7 habitantes por oficina), lo que corrobora una búsqueda de la centralidad para este tipo de servicios. En este espacio, se concentra además la mayor diversidad de entidades, de manera que se constata que la reorganización ha llevado a reforzar el factor de la centralidad como estrategia para mantener la visibilidad de las entidades en casos en los cuales el cierre de oficinas ha afectado a casi toda la ciudad. Este proceso también se observa para entidades que todavía mantienen varias sucursales abiertas en la ciudad y donde las sucursales que permanecen abiertas en los barrios han elegido prioritariamente las principales arterias de cada distrito. 
Algunos distritos que rodean el espacio central consolidado (Universidad, Casablanca y Actur-Rey Fernando) han perdido proporcionalmente menos oficinas que otros barrios, debido a que cuentan con una población menos envejecida y cuyas rentas personales son más altas, como más adelante se analiza. En el caso de barrios obreros tradicionales, donde se concentra una elevada proporción de población de origen extranjero y/o población muy envejecida, las pérdidas de oficinas han sido muy importantes, hasta superar el porcentaje medio de cierres en la ciudad. Esta situación se detecta en Delicias (de 126 oficinas en 2008 pasa a 52 en 2019), Las Fuentes (de 37 a 12), La Almozara (de 22 a 8), Torrero-La Paz (de 18 a 9) o El Rabal (de 67 a 29). También se da una situación semejante a la de estos barrios en el Casco Histórico, espacio envejecido, con rentas medias o bajas y con una proporción elevada de población de origen extranjero, donde se ha pasado de 46 a 26 oficinas abiertas y una ratio de $2.360,5$ habitantes por oficina. Sin embargo, internamente se aprecian diferencias notables entre la zona central del Casco Histórico, renovada urbanísticamente y con gran actividad de servicios, y los barrios más deprimidos de San Pablo y La Madalena. Son ejemplos de espacios urbanos que han perdido una importante presencia física de oficinas con relación a las que tenían, cuando los rasgos demográficos de su población apuntan sin embargo a que son áreas con población que requiere la presencialidad de las sucursales al reunir perfiles sociodemográficos con escaso acceso a los canales digitales, tanto por edad como por escasos recursos económicos. Ello configura problemas de acceso y cobertura porque cada vez tienen menos oficinas, pero también una menor variedad de entidades en su espacio próximo, con la pérdida además del vínculo personal con una oficina de referencia.

Por otra parte, el desarrollo de nuevos espacios residenciales creados o consolidados a partir de la expansión inmobiliaria de comienzos del siglo XXI (Sur, Miralbueno, Oliver-Valdefierro) no ha ido acompañado por la apertura de sucursales, lo que parece responder a las nuevas estrategias de las entidades financieras para no expandir más físicamente sus redes; por tanto, los cierres en estos espacios han sido proporcionalmente menores, porque desde su inicio la presencia de oficinas físicas es muy escasa. En estos barrios, la ratio de habitantes por oficina presenta las peores cifras entre los barrios urbanos: Sur $(9.693,5)$, Oliver-Valdefierro $(4.639,1)$ o Miralbueno $(4.268,7)$. Sin embargo, y como avanzan algunas investigaciones (Hernando y Nieto, 2006), estos espacios preconizan el nuevo modelo donde los servicios de la banca electrónica suplirán la proximidad que están ofreciendo las oficinas de barrio.

Otros espacios, como los Barrios Rurales, pequeños núcleos de población pertenecientes al municipio de Zaragoza pero con un tipo de hábitat residencial de baja densidad o con urbanizaciones aisladas, tenían una menor presencia de oficinas y han registrado también, proporcionalmente, menos cierres. Sin embargo, en 2019 su cobertura se sitúa entre las mejores de la ciudad, con 1.577,6 habitantes por oficina. En estos núcleos periurbanos, destaca la implantación de sucursales de Ibercaja, que, como entidad líder regional, cuenta con una elevada penetración en el espacio rural. 
Esta reconfiguración del paisaje físico bancario sufrida por la ciudad se complementa con el incremento del uso de la banca on-line, a la que las propias entidades están dirigiendo determinadas actividades, sobre todo, ante la saturación de clientes por oficina. Las propias entidades están estudiando los perfiles de los clientes, y esto ha llevado a una mínima presencia de oficinas en barrios nuevos donde predomina la población joven y adaptada al uso de las plataformas digitales. Por ejemplo, Valdespartera, un barrio de reciente creación (2009) ubicado en el distrito Sur y con algo más de 16.000 habitantes, tiene tan solo dos oficinas bancarias, lo que ofrece una ratio de unas 8.000 personas por oficina. Un estudio reciente sobre el uso de la banca electrónica refleja que es el barrio de Zaragoza con mayor uso de la banca on-line $e^{5}$. Un patrón similar se da en otros barrios como Parque Goya (casi 9.000 habitantes y una oficina) y Parque Venecia (más de 4.000 habitantes y una oficina), todos ubicados en la periferia urbana y que, sin embargo, presentan algunos problemas de continuidad con la ciudad consolidada que incrementan los desequilibrios espaciales (Escolano-Utrilla et al., 2018) y el acceso a los servicios existentes en los barrios contiguos.

La reorganización bancaria lleva a que la población tenga un menor grado de acceso a las oficinas, para lo que hemos medido la accesibilidad de la población a las oficinas mediante el análisis espacial de la disponibilidad de oficinas relacionándolas con los datos demográficos sobre cada sección censal y manzana de la ciudad.

La comparativa entre 2011 y 2019 (figuras 3 y 4) permite observar claramente como muchas de las secciones censales han perdido la posibilidad de tener cerca una sucursal bancaria. Si en 2011 tan solo el 8\% de la población de la ciudad no tenía a menos de 300 metros una entidad financiera (en espacios urbanos no consolidados en la periferia), en 2019 el 20\% de la población (más de 145.000 habitantes) no dispone de ninguna entidad en la distancia establecida. Respecto a la población con una entidad accesible y, por lo tanto, sin posibilidad de elección, en 2011 correspondía al 10\%, mientras que en 2019 el porcentaje se incrementa hasta el 20\%. Estas cifras indican un fuerte empeoramiento de la proximidad física, ya que actualmente el $40 \%$ de la población de la ciudad (287.255 habitantes) no tiene acceso a una entidad o solamente a una en su espacio próximo. Respecto a la variación en áreas con gran diversidad financiera, en 2011 el 47\% de la población tenía acceso a seis o más entidades distintas a menos de 300 metros de su residencia, mientras que en 2019 solo el $22 \%$ tiene acceso a este nivel de diversidad.

En 2011 la mayoría de los residentes en el espacio urbano consolidado (Centro, ensanches y barrios populares como Delicias, Las Fuentes, San José o Torrero-La Paz) disponían de seis o más entidades diferentes a menos de 300 metros, por lo que el grado de accesibilidad era más alto. Por el contra-

5. El análisis se realizó en 2017 para el grupo bancario Ibercaja en un trabajo académico sin publicar. 
Figura 3. Accesibilidad de la población a entidades financieras a 300 metros en 2011 y 2019

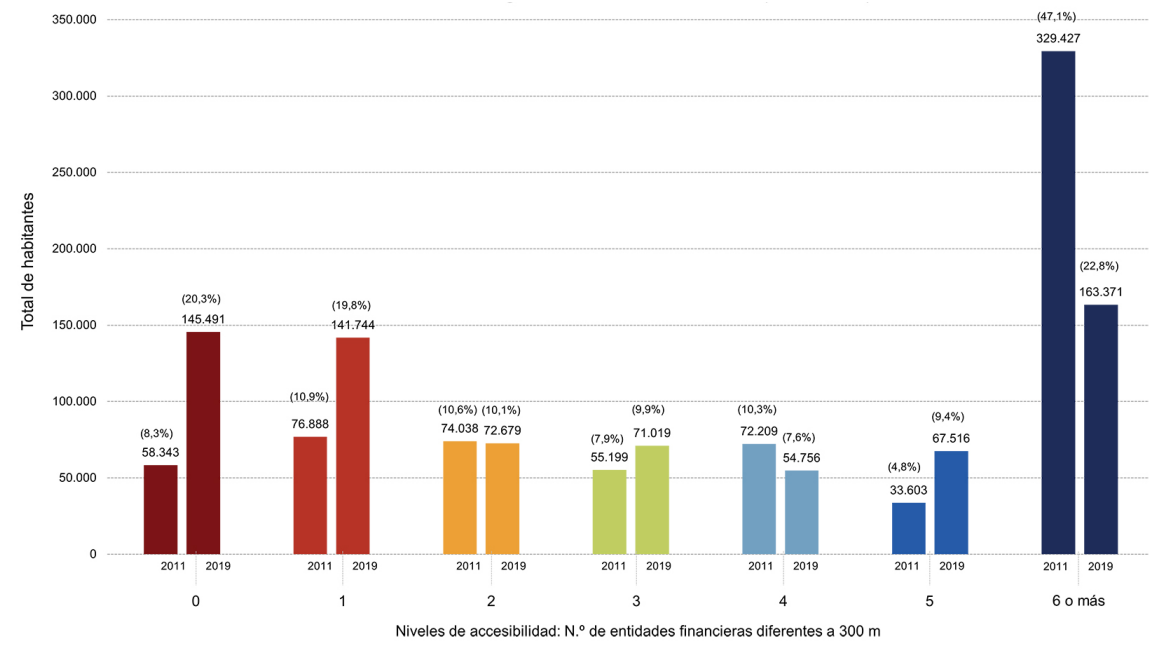

Fuentes: Padrón Municipal de Habitantes del Ayuntamiento de Zaragoza y Grupo de Estudios en Ordenación del Territorio. Elaboración propia, 2020.

rio, los barrios de reciente creación o expansión (Sur, Miralbueno, OliverValdefierro, Santa Isabel) disponían de una mala accesibilidad a entidades físicas. En 2019, la situación es muy distinta, se han reducido en las áreas urbanas con elevada accesibilidad y tan solo el centro de la ciudad y los espacios centrales de algunos barrios siguen presentando una proximidad a los servicios bancarios con una buena diversidad de la oferta. El análisis realizado a escala de manzana permite corroborar con más detalle la situación de falta de proximidad actual de oficinas bancarias en muchos espacios urbanos (figura 5).

Junto a la pérdida de accesibilidad a una sucursal, interesa saber qué grupos de población pueden verse más afectados. Para ello, se plantea el análisis de la relación existente entre el cierre de oficinas bancarias, el nivel de renta personal, la tasa de desempleo y el envejecimiento — población mayor de 65 años(figura 6). La selección de estas variables permite identificar la presencia de grupos vulnerables por su negativa situación económica o de edad a la hora de acudir a una sucursal que cada vez tienen más alejada de su domicilio y donde no existen lazos de confianza con el cliente. El análisis de la relación de variables se presenta con una cartografía a escala de sección censal con leyenda de doble entrada (envejecimiento y renta), y que muestra el número de cierres de oficinas por volumen y la tasa de desempleo en la base de cada sección. Esto permite apreciar como los barrios obreros tradicionales (Delicias, Las Fuentes, La Almozara, El Rabal, Casco Histórico o San José) se corresponden con espacios muy envejecidos, con altas tasas de paro y con rentas bajas, donde además se ha asentado una alta proporción de población extranjera con esca- 
Figura 4. Accesibilidad de la población a entidades financieras a 300 metros en 2011 y 2019 por sección censal

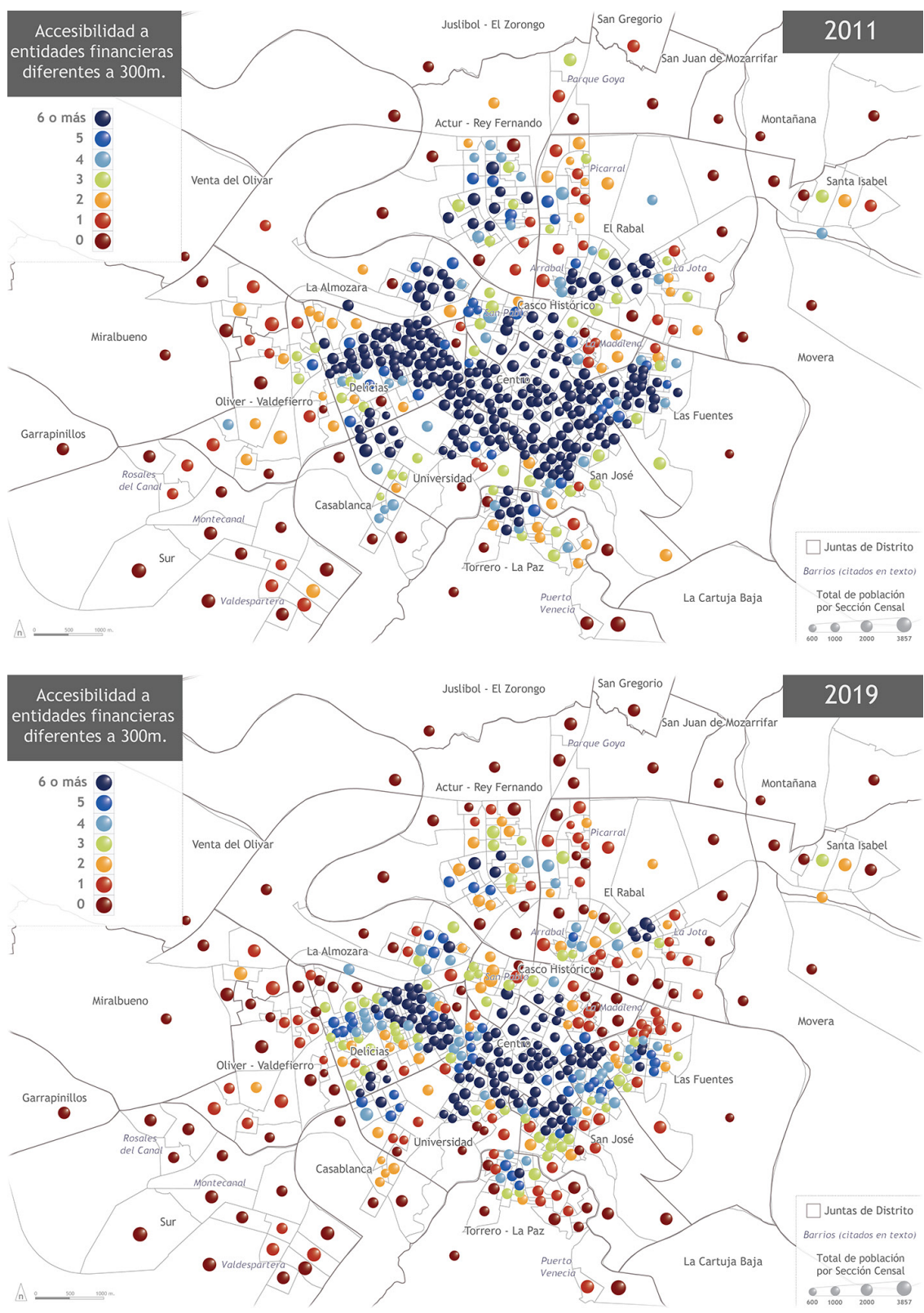

Fuentes: Padrón Municipal de Habitantes del Ayuntamiento de Zaragoza y Grupo de Estudios en Ordenación del Territorio. Elaboración propia, 2020. 
Figura 5. Accesibilidad de la población a entidades financieras a 300 metros en 2019 por manzana

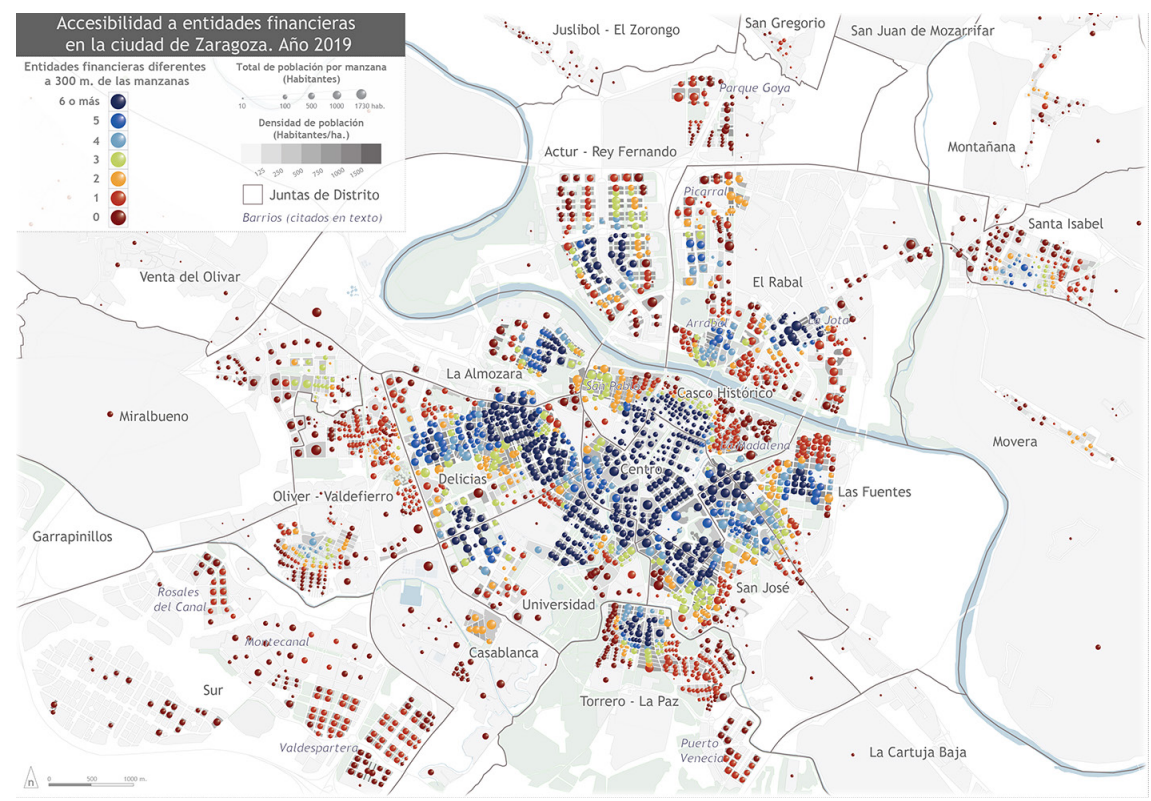

Fuentes: Padrón Municipal de Habitantes del Ayuntamiento de Zaragoza y Grupo de Estudios en Ordenación del Territorio. Elaboración propia, 2020.

sos recursos económicos. Estos barrios son también, como ya se ha indicado, los que desde 2008 han perdido mayor número de oficinas con relación a las que tenían antes de la crisis, ya que han quedado abiertas menos del 50\%. Se confirma así como en el proceso de reorganización de las entidades existe una tendencia hacia el cierre de sucursales en barrios con bajos niveles de renta y con una dependencia de atención personal.

Por su parte, el distrito Centro es el espacio con mayores rentas y mejores tasas de empleo, aunque también cuenta con una población envejecida. Es la principal área funcional de la ciudad para la provisión de todo tipo de servicios especializados, por lo que históricamente es aquí donde las entidades bancarias han tenido sus sedes y delegaciones. Sin embargo, en el periodo analizado se ha cerrado también un importante número de oficinas, principalmente para evitar la duplicidad de las redes tras los procesos de fusiones y absorciones entre entidades. A su vez, ciertas entidades han reconvertido algunas de sus principales oficinas en agencias "digitales o inteligentes», como han hecho CaixaBank (Store), BBVA (Oficina digital) o Ibercaja (Xplora) en el paseo de la Independencia, principal eje funcional de la ciudad, con el objetivo de reforzar la experiencia de los clientes en las oficinas y dar a conocer las potencialidades de la banca digital (figura 7). 
Figura 6. Relación del nivel de renta personal, tasa de desempleo y población de 65 y más años con el cierre de oficinas

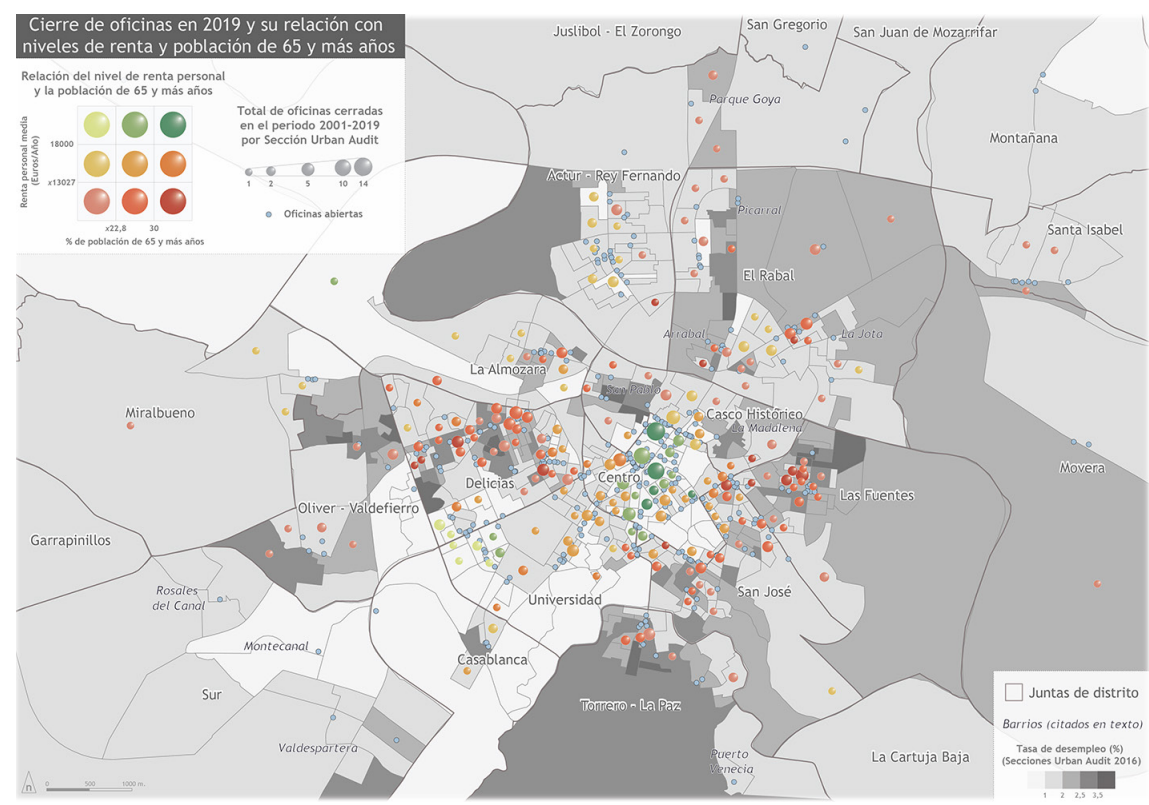

Fuentes: Padrón Municipal de Habitantes del Ayuntamiento de Zaragoza, Grupo de Estudios en Ordenación del Territorio y Urban Audit. Elaboración propia, 2020.

De este modo, el Centro ha visto reforzada su centralidad por la gran atracción que ejerce para realizar las operaciones más especializadas y porque continúa albergando las sedes — con domicilio fiscal— de las entidades de origen regional (Ibercaja y Caja Rural de Aragón), las delegaciones territoriales de las principales entidades nacionales (Santander, BBVA, CaixaBank, Sabadell, Bankia, Kutxabank, entre otras) y las oficinas de representación de las demás entidades con presencia en la ciudad. De forma específica, en 2019 el distrito Centro acoge las oficinas de varias entidades que únicamente disponen de sucursal en esta zona de la ciudad, entre las que destacan la banca de inversión, especializada, privada o de representación (Banca March, Renta 4 Banco, UBS, Santander Private Banking, Andbank, Inversis, Arquia Banca, Caja de Ingenieros, ING, Novo Banco, Caixa Geral, Triodos Bank, Banco Pichincha, Caja Rural de Teruel, Abanca, Unicaja). Así pues, el Centro se ha consolidado como el área funcional especializada en actividades financieras y bancarias, con una gran presencia de estas sedes y oficinas de representación en el entorno de la delegación del Banco de España.

En otros espacios que rodean a la trama urbana consolidada (Universidad, Casablanca, Actur-Rey Fernando, El Rabal), la pérdida de oficinas no ha sido tan acusada como en el resto de la ciudad, probablemente porque tienen una población menos envejecida, mayor renta y menor tasa de desempleo que los 
Figura 7. Oficinas digitales e inteligentes de CaixaBank, BBVA e Ibercaja en Zaragoza

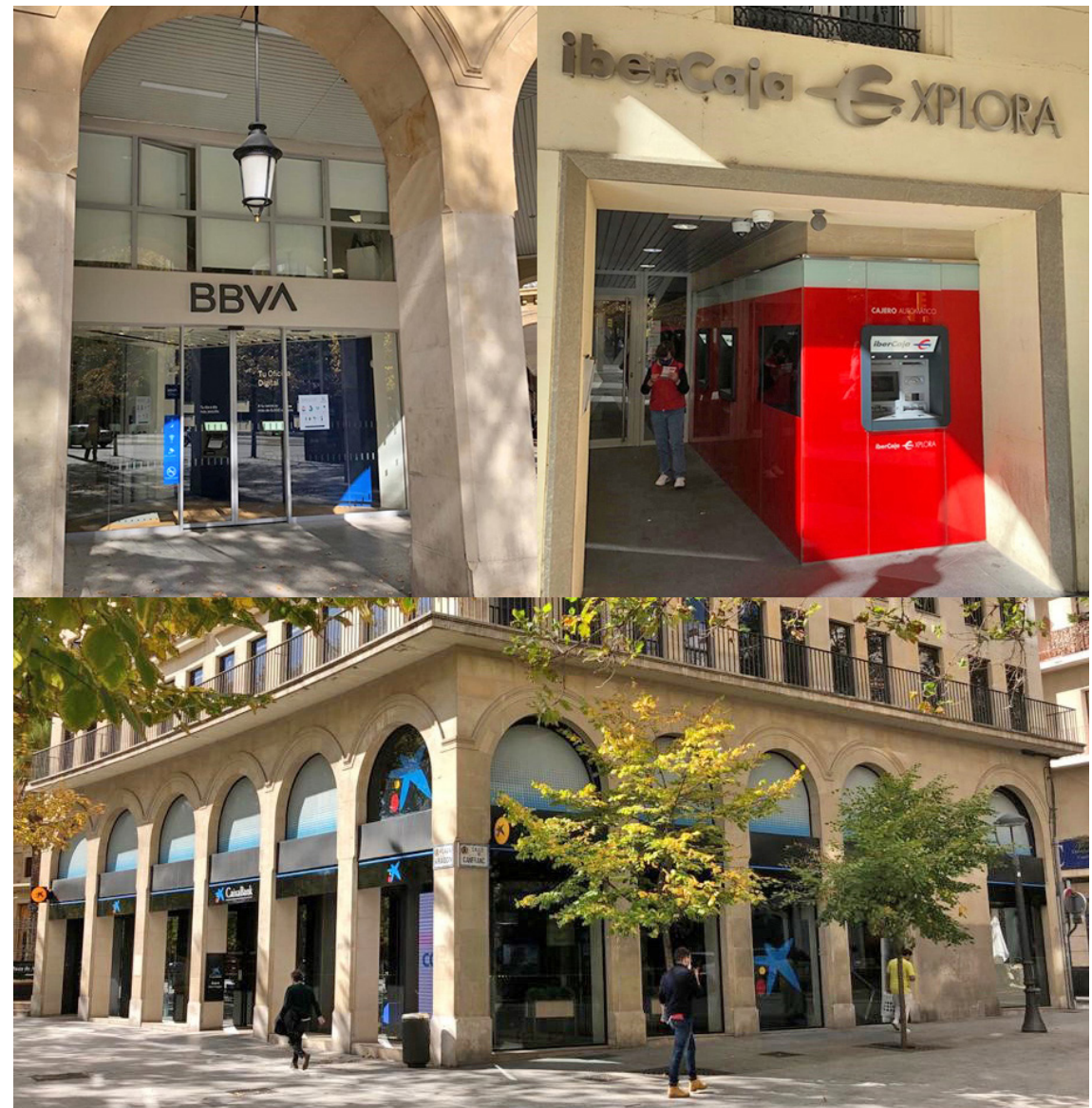

Fuente: Fotografías de los autores, 2020.

barrios tradicionales. De todos modos, es cierto que son barrios muy extensos, y algunas de sus secciones están envejecidas y cuentan con rentas más bajas (como La Jota, Arrabal o Picarral), y además se aprecia un comportamiento similar al de los barrios tradicionales descritos anteriormente.

El resto de las áreas urbanas, como los barrios de reciente desarrollo en las orlas externas de la ciudad (Valdespartera, Rosales del Canal, Montecanal, Parque Venecia, Miralbueno, Parque Goya), son espacios de rentas mediasaltas, poco envejecidos y con bajas tasas de desempleo. En estos espacios, el problema no es el cierre de oficinas, sino que las entidades ya adoptaron aquí la estrategia de no ubicar sucursales y apostar por la banca electrónica como alternativa, por lo que apenas se han producido cierres. 


\section{Conclusiones}

El proceso de reestructuración bancaria originado tras la Gran Recesión presenta efectos territoriales en las ciudades españolas producto de la concentración de entidades bancarias, de los reajustes para reducir costes y del crecimiento de la banca electrónica. Entre las consecuencias más evidentes, están las fusiones/ absorciones de entidades financieras y la reorganización de las redes de atención física, lo que ha supuesto una reducción muy importante de oficinas bancarias para evitar la duplicidad de sus nuevas redes.

La disminución de oficinas físicas está generando nuevos paisajes urbanos en torno a los servicios financieros, ya que se ha pasado de tener un elevado número de sucursales que permitían una alta proximidad a una ausencia o escasez de estos servicios en determinados espacios urbanos. Estos procesos tienen su origen en la búsqueda de una mayor rentabilidad de las entidades bancarias, que reducen su presencia física para ahorrar costes aprovechando a su vez las ventajas que ofrece la digitalización del sector. En términos espaciales, ello supone una mayor concentración de la actividad bancaria y la pérdida de la proximidad y de la gran penetración territorial que han caracterizado a este servicio durante las últimas décadas. Las entidades han aprovechado además este proceso para incrementar y acelerar el uso de las plataformas tecnológicas para ofrecer sus servicios, aunque no toda la población puede acceder a los canales digitales por falta de recursos o por la brecha digital.

En este artículo nos hemos centrado en la escala urbana tomando como caso de estudio la ciudad de Zaragoza como ejemplo de ciudad media. En concreto, se ha analizado la trayectoria de las oficinas bancarias desde el inicio del proceso de reestructuración tras la crisis financiera de 2008 hasta 2019, en la antesala de la pandemia de la COVID-19. Para ello, se han valorado los patrones de cobertura y accesibilidad a los servicios bancarios, lo que permite observar la desigualdad espacial en las condiciones de uso y acceso a estos servicios desde diferentes espacios y a distintas escalas urbanas. El resultado espacial del proceso de reorganización de las entidades financieras conduce a un refortalecimiento de la centralidad física de la actividad bancaria por su concentración en el centro urbano funcional y los subcentros de barrio, que han ganado peso al cerrar buena parte de las oficinas en el conjunto de la ciudad. Esta estrategia de las entidades busca ubicarse en espacios con mayores dotaciones comerciales y empresariales, o zonas atractivas por su proximidad a equipamientos estructurantes como oficinas de la Administración, docentes o sanitarios. Como resultado, han disminuido la accesibilidad y la proximidad a los servicios bancarios en gran parte de la ciudad, en especial en los barrios más envejecidos, con menores rentas y alejados de los espacios funcionales.

En definitiva, la reorganización observada en la ciudad de Zaragoza es coherente con las dinámicas de repliegue de oficinas bancarias hacia los espacios centrales, acorde con el nuevo modelo bancario surgido tras la reorganización y bancarización de las antiguas cajas de ahorros, que se ubicaban de forma más distribuida y equitativa por la ciudad, pero que ahora deben también optimizar costes. La búsqueda de ubicaciones estratégicas garantiza la visibilidad de las 
entidades y, a pesar de la gran pérdida de cobertura a la población, continúa presentando unos niveles adecuados para este servicio, aunque cabrá estar pendiente de cómo avanzan los procesos de reorganización tras las nuevas fusiones previstas entre entidades.

Como consecuencia, se están configurando espacios con escasa accesibilidad y baja diversidad de entidades para la población en sus entornos de proximidad o escala de barrio, lo que en la práctica supone que una parte de la población queda marginada en el uso de los servicios financieros por sus perfiles socioeconómicos: población envejecida con problemas de movilidad, bajo nivel de ingresos y mayores tasas de desempleo. Es decir, se produce allí donde residen los grupos de población más vulnerables, lo que supone hallar indicios de hacia dónde deben dirigirse las futuras líneas de investigación para profundizar en el conocimiento de la exclusión financiera.

Otra cuestión relevante es cómo la banca digital se ofrece como alternativa ante la reducción de oficinas físicas, aunque ello puede aumentar los problemas de exclusión, ya que hay grupos que por su edad, formación, situación económica, prácticas culturales o ideológicas e, incluso, lugar de residencia no tienen acceso a estos servicios digitales.

Por último, cabe señalar que la situación generada por la COVID-19 ha acelerado la digitalización de los servicios bancarios, puesto que la pandemia ha llevado a que las entidades adopten estrategias de reducción generalizada de los puntos de atención presencial, lo que preconiza el futuro del modelo bancario en España. En Zaragoza, durante el periodo de confinamiento se ha observado una diferencia entre las redes de las antiguas entidades regionales (como Ibercaja o CaixaBank), que han mantenido abiertas la mayor parte de oficinas, frente a los bancos tradicionales (como BBVA o Santander), que tan solo han mantenido abierto un pequeño porcentaje de sus sucursales, aunque sus empleados han implementado el teletrabajo para continuar atendiendo a los clientes. Esta situación ha puesto de manifiesto la existencia de muchos grupos sociales con problemas de acceso a las redes virtuales, que han tenido que pedir ayuda para tener un mínimo acceso a los servicios bancarios. En el mismo sentido, la concentración de oficinas en espacios centrales supone una limitación para la provisión de servicios de proximidad que va en contra de las tendencias actuales de planificación urbana, que persiguen modelos con barrios multifuncionales y servicios de proximidad para lograr ciudades más sostenibles y que minimicen los desplazamientos.

\section{Referencias bibliográficas}

Alamá, Luisa y Tortosa-Ausina, Emili (2012). «Bank branch geographic location pattern in Spain: some implications for financial exclusion». Growth and Change, 1 (43), 505-543.

$<$ https://doi.org/10.1111/j.1468-2257.2012.00596.x>

Alonso Logroño, María Pilar; Pueyo Campos, Ángel; Postigo Vidal, Raúl; López Escolano, Carlos y Rubio Gracia, José Luis (2014a). «La reestructuración del sector financiero». En: Albertós, J. M. y Sánchez Hernández, J. L. (coords.). 
Geografía de la crisis económica en España. Valencia: Prensas de la Universitat de València, 305-328.

Alonso Logroño, María Pilar; Pueyo Campos, Ángel; Postigo Vidal, Raúl y López Escolano, Carlos (2014b). «Los efectos de la crisis financiera en la implantación territorial de los servicios bancarios: el caso de la ciudad de Zaragoza». En: Albertós Puebla, J. M. y Sánchez Hernández, J. L. (coords.). Geografía de la crisis económica en España. Valencia: Prensas de la Universitat de València, 411-434.

Alonso logroño, María Pilar; Oliveira, Juliana y Fernández, Fabio (2020). «Dinámicas espaciales recientes de las redes bancarias de España y Brasil: un estudio de las ciudades de Lleida y Presidente Prudente». En: Alonso Logroño, M. P.; Sá Marques, T. y Santos, H. (coords.). La geografía de las redes económicas y la geografía económica en red. Oporto: Faculdade de Letras da Universidade do Porto, Asociación de Geógrafos Españoles, 177-188.

Banco Central Europeo (BCE) (2019). Anuario del Banco Central Europeo. Recuperado de <https://www.ecb.europa.eu/pub/pdf/annex/ecb 10913d25c1.pr190604_ ssi_table.pdf $>$.

BANCO DE España (2020a). «Escenarios macroeconómicos de referencia para la economía española tras el Covid-19». Boletín Económico, 2, 1-33.

- (2020b). «Entidades de crédito y establecimientos financieros de crédito». Boletín Estadístico. Recuperado de <https://www.bde.es/webbde/es/estadis/infoest/bolest4. html>.

Boufounou, Paraskevi V. (1995). «Evaluating bank branch location and performance: A case study». European Journal of Operational Research, 87, 389-402.

Carbó, Santiago (2017). «Mitos y realidades de la digitalización financiera. Los medios de pago como paradigma». Mediterráneo Económico, 29, 139-149.

Chakravarty, Shanti (2006). "Regional variation in banking services and social exclusion». Regional Studies, 40 (4), 415-428.

Delgado, Javier; Saurina, Jesús y Townsend, Robert (2008). «Estrategias de expansión de las entidades de depósito españolas. Una primera aproximación descriptiva». Revista de Estabilidad Financiera, 15, 99-117.

Demirgüç-Kunt, Asli; Klapper, Leora; Singer, Dorothe; Ansar, Saniya y Hess, Jake (2018). The Global Findex Database 2017: Measuring Financial Inclusion and the Fintech Revolution. Washington, DC: World Bank. <https://doi.org/10.1596/978-1-4648-1259-0>

DíAz, Eva (14 de octubre de 2020). «Unicaja y Liberbank tendrán que cerrar 300 oficinas en 14 provincias». elEconomista.es. Recuperado de <https:/www.eleconomista. es/empresas-finanzas/noticias/10824186/10/20/Unicaja-y-Liberbank-tendran-quecerrar-300-oficinas-en-14-provincias.html>.

El Periódico (4 de septiembre de 2020). «Barclay’s calcula que la fusión entre Bankia y CaixaBank supondrá el cierre de 1.440 oficinas». elPeriódico. Recuperado de $<$ https://www.elperiodico.com/es/economia/20200904/barclays-calcula-que-lafusion-entre-bankia-y-caixabank-supondra-el-cierre-de-1440-oficinas-8099611>.

Escolano-Utrilla, Severino; López-Escolano, Carlos y Pueyo Campos, Ángel (2018). «Urbanismo neoliberal y fragmentación urbana: el caso de Zaragoza (España) en los primeros quince años del siglo xxI». Eure, 44 (132), 183-210.

Europa Press (18 de agosto de 2020). «El 31\% de los españoles aumenta el uso de banca "online" por la pandemia, según ING». Europa Press. Recuperado de $<$ https://www.europapress.es/economia/finanzas-00340/noticia-31-espanolesaumenta-uso-banca-online-pandemia-ing-20200818113016.html>. 
Fernández-Olit, Beatriz; Ruza, Cristina; Cuesta-González, Marta de la y MatiLla-Garcia, Mariano (2019). "Banks and Financial Discrimation: What Can Be Learnt from the Spanish Experience?». Journal of Consumer Policy, 42, 303-323. <https://doi.org/10.1007/s10603-019-09412-5>

Fondo Monetario Internacional (2020). «Perspectivas de la economía mundial, abril de 2020. Capítulo 1». Recuperado de <https://www.imf.org/es/Publications/ WEO/Issues/2020/04/14/weo-april-2020>.

Fuentelsaz, Lucio; González, Minerva y Palomas, Sergio (2016). "La reestructuración de la red de oficinas en la banca española durante la crisis». Cuadernos Económicos de ICE, 92, 175-198.

García Cabello, Julia (2019). «A decision model for bank branch site selection: Define branch success and do not deviate». Socio-Economic Planning Sciences, 68. <http://dx.doi.org/10.1016/j.seps.2017.09.004>

Garrocho-Rangel, Carlos Félix y Campos-Alanís, Juan (2010). «Organización espacial del sistema bancario dentro de la ciudad: estrategia territorial, accesibilidad y factores de localización». Economía, Sociedad y Territorio, 10 (33), 413-453.

Gonzalo, Ángeles (9 de septiembre de 2020). "La banca cerrará cerca de 4.000 oficinas entre este año y el próximo». Cinco Días. Recuperado de $<$ https://cincodias. elpais.com/cincodias/2020/09/08/companias/1599588614_146916.html>.

Gutiérrez Fernández, Milagros; Palomo Zurdo, Ricardo y Romero Cuadrado, María (2012). «La expansión territorial como factor motivador de la reestructuración del sistema financiero español: el caso de las cajas de ahorros y las cooperativas de crédito". REVESCO, Revista de Estudios Cooperativos, 107, 7-34.

Hauswald, Robert y Marquez, Robert (2006). "Competition and strategic information acquisition in credit markets». Review of Financial Studies, 19 (3), 967-1.000. <https://doi.org/10.1093/rfs/hhj021>

Hernando, Ignacio y Nieto, María J. (2006). «Is the Internet delivery cannel changing banks' performance? The case of Spanish banks». Journal of Banking \& Finance, 31 (4), 1.083-1.099. $<$ https://doi.org/10.1016/j.jbankfin.2006.10.011>

Huysentruyt, Marieke; Lefevere, Eva y Menon, Carlo (2013). «Dynamics of retailbank branching in Antwerp (Belgium) 1991-2006: Evidence from micro-geographic data». Journal of Banking \& Finance, 37 (2), 291-304. <https://doi.org/10.1016/j.jbankfin.2012.08.023>

Instituto Valenciano de InVestigaciones Económicas (IVIE) (2018). «Accesibilidad financiera». Valencia. Base de datos disponible en internet. <https://www. ivie.es/es_ES/bases-de-datos/diferencias-economicas-y-sociales-de-los-territorios/ accesibilidad-financiera/>.

Isard, Walter (1956). Location and the Space Economy. Nueva York: The Technology Press of Massachusetts Institute of Technology y John Wiley \& Sons.

Jackowicz, Krzysztof; KozŁowski, Łukasz y WnUCzaK, Paweł (2020). «Which local markets do banks desert first? Evidence from Poland». Finance Research Letters [en prensa].

Jiménez Gonzalo, Concepción y Tejero Sala, Helena (2018). "Cierre de oficinas bancarias y acceso al efectivo en España». Revista de Estabilidad Financiera, 34, 35-57.

Kempson, Elaine (2006). "Policy level response to financial exclusion in developed economies: lessons for developing countries». Access to Finance: Building Inclusive Financial Systems. Washington DC: World Bank. 
Labasse, J. (1974). L'Espace financier, analyse géographique. París: Collection U, Géographie. Armand Colin.

Leyshon, Andrew y Thrift, Nigel (1995). "Geographies of financial exclusion: financial abandonment in Britain and the United States». Transactions of the Institute of British Geographers, 20 (3), 312-341. <https://doi.org/10.2307/622654>

- (1996). "Financial exclusion and the shifting boundaries of the financial systems». Environment and Planning A, 28, 1.150-1.156.

Leyshon, Andrew; French, Shaun y Signoretta, Paola (2008). "Financial exclusion and the geography of bank and building society branch closure in Britain». Transactions of the Institute of British Geographers, 33, 447-465.

Martín-Oliver, Alfredo (2018). «Financial exclusion and branch closures after the Great Recession». Regional Studies, 53 (4), 562-573. <https://doi.org/10.1080/00343404.2018.1462485>

Maudos Villarroya, Joaquín (2014). «Reestructuración bancaria y accesibilidad financiera». Cuadernos de Información Económica, 238, 103-119.

- (2017). «El acceso a los servicios bancarios en España. El impacto de la reducción del número de oficinas». Mediterráneo Económico, 29, 265-286.

Méndez Gutiérrez del VAlle, Ricardo (2018). La telaraña financiera. Una geografía de la financiarización y su crisis. Santiago de Chile: RIL Editores. Colección Estudios Urbanos UC.

Molina, David (2016). Fintech: Lo que la tecnología hace por las finanzas. Barcelona: Profit Editorial.

Moreno, Antonio y Escolano, Severino (1992). El comercio y los servicios para la producción y el consumo. Madrid: Editorial Síntesis.

Moses, Leon y Williamson, Harold F. (1967). «The Location of Economic Activity in Cities». The American Economic Review, 57 (2), 211-222.

OrTaköy, Selman y Özsürünç, Zehra (2019). «The Effect of Digital Channel Migration, Automation and Centralization on the Efficiency of Operational Staff of Bank Branches». Procedia Computer Science, 158, 938-946. <https://doi.org/10.1016/j.procs.2019.09.134>

Romero, Víctor (12 de septiembre de 2020). «Valencia y Madrid cerrarán más oficinas que Cataluña en la fusión de CaixaBank y Bankia». El Confidencial. Recuperado de <https:/www.elconfidencial.com/empresas/2020-09-12/valencia-madridandalucia-oficinas-fantasma-caixa-bankia_2744524/>.

Rojas, Laura (2016). La revolución de las empresas FinTech y el futuro de la Banca. Disrupción tecnológica en el sector financiero. CAF, Banco de Desarrollo de América Latina. Serie Políticas Públicas y Transformación Productiva, 24.

Ruiz-Hernández, Diego; Delgado-Gómez, David y López-Pascual, Joaquín (2015). «Restructuring bank networks after mergers and acquisitions: A capacitated delocation model for closing and resizing branches». Computers and Operations Research, 62, 316-324. $<$ http://dx.doi.org/10.1016/j.cor.2014.04.011>

SAMPEDRO, Rubén (2 de abril de 2020). «Las fusiones bancarias se acelerarán por la crisis del coronavirus». Expansión. Recuperado de <https://www.expansion.com/ empresas/banca/2020/04/02/5e84f699468aebd5528b45e2.html>.

Tolentino, Marta; Jareño, Francisco y Rubio, Rocío (2018). "The effect of bank restructuring on the issuance of preferred shares in Spain». Revista Galega de Economia, 27 (1), 123-143.

<http://dx.doi.org/10.15304/rge.27.1.5231> 
Vives, Xavier (2019). «Competition and stability in modern banking: A post-crisis perspective». International Journal of Industrial Organization, 64, 55-69. <https://doi.org/10.1016/j.ijindorg.2018.08.011>

Zuliani, Jean-Marc (2013). "Les services bancaires et d'assurances et les services informatiques dans les villes moyennes du Grand Sud-Ouest français, logiques de déploiement et stratégies d'ancrage». Geographicalia, 63-64, 235-270. <https://doi.org/10.26754/ojs_geoph/geoph.201363-64861>

Zuloaga, Jorge (30 de marzo de 2020). «El coronavirus pone en riesgo de extinción la mitad de las oficinas bancarias». El Confidencial. Recuperado de <https://www. elconfidencial.com/empresas/2020-03-30/coronavirus-pone-peligro-extincionmitad-oficinas-bancarias_2517631/>.

- (14 de abril de 2020). «La banca cierra la mitad de sus oficinas por el coronavirus y las cajas solo un 10\%». El Confidencial. Recuperado de <https://www.elconfidencial.com/empresas/2020-04-14/banca-cierra-mitad-oficinas-coronavirus-cajassolo-diez-por-ciento_2546676/>. 
